\title{
GEOMETRIA 3D DE FALHAS DE EMPURRÃO E DOBRAS ASSOCIADAS COMO EXPRESSÕES DA MORFOLOGIA DO DESCOLAMENTO BASAL: RESULTADOS DE UMA SIMULAÇÃO COMPUTACIONAL
}

\author{
VASSILY KHOURY ROLIM \& FERNANDO FLECHA ALKMIM
}

\begin{abstract}
D THRUST FAULT GEOMETRY AS AN EXPRESSION OF THE ASSOCIATED DETACHMENT MORPHOLOGY: RESULTS OF A COMPUTER SIMULATION Most two-dimensional fault propagation fold models are based upon the development and migration of kink bands and assume constant dips along each band, constant layer thickness and conservation of the section area. Modelling a fault-propagation fold requires the determination of the position and of the angle of each kink line that defines the structure. Once modelling a series of dip sections of a fault propagation fold, it is possible to generate three dimensional (3D) geometrical models by linking a large number of these sections. A computer program was created to generate $3 \mathrm{D}$ geometrical models of single thrusts or imbricate fans. Using the program, a series of experiments were run to study the influence of the detachment morphology on geometry of the associated fault ramps. After modelling under variable conditions, following results were obtained: (a) the fault ramp surface is non-planar if the detachment surface is also non-planar and the ramp surface reflects all irregularities of the detachment surface; (b) the trace of a thrust fault on a map is similar to the trace of the associated detachment surface along a strike section: the fault trace is straight when the detachment surface is flat and is curved when the detachment surface is curved. Depressions in the detachment surface correspond to antitaxial curves (salients) in the fault surfaces. Detachment highs, in contrary, correspond to sintaxial curves (recesses) in the fault surfaces. The expressions of the deepest and the shallowest points of the detachment are, respectively, the salient and the recess culminations. It is concluded that if indenters are not active during thrust nucleation and if no later deformation occurs, the 3D shape of single thrust fault and of thrust systems is determined by the morphology of the associated detachment. Simulation of the development of an imbricate fan linked to a trough-shaped detachment surface and its comparison with results of a natural example given by the Dom Bosco thrust system of the southern Quadrilatero Ferrífero, Brazil, resulted in a close correlation between the models and the Dom Bosco system. In both cases, faults exhibit pronounced curvature with increasing dips toward the hinterland. Fault traces converge in the areas of minimal depths of the detachment surface and diverge in the areas of maximal detachment depth.
\end{abstract}

Keywords: structural geology. computer modeling, fault related folds

Resumo Um modelo geométrico-cinemático bidimensional de uma dobra por propagação de falha pode ser construído para seções paralelas ao mergulho da falha, utilizando equações que determinam as inclinações das camadas dobradas e os limites das "kink bands". que definem a estrutura. Por outro lado, a configuração 3D do mesmo sistema pode ser obtida por meio da integração de grande número de modelos bidimensionais. A junção de pontos entre as seções origina o desenho tridimensional, contendo as camadas, a superfície de descolamento e a rampa da falha. Um programa computacional foi desenvolvido para implementar este modelo matemático. Com seu uso geraram-se inúmeras situações geológicas distintas e estudou-se a influência da morfologia da superfície de descolamento na geometria das falhas de empurrão e dobras associadas. As simulações computacionais tridimensionais permitiram concluir, em primeira aproximação, que seções verticais isoladas pouco revelam a geometria 3D dos sistemas de falhas. Além disso, mostram que o traço da rampa de falha em mapa é um fiel espelho da topografia da superfície de descolamento. O traço da falha é retilíneo, quando a superfície de descolamento for plana e é curvo, quando a superfície for curva. Convexidades da superfície de descolamento (altos) expressam-se como saliências (convexidades voltadas para o antepaís) nos traços horizontais das falhas, já concavidades (baixos) expressam-se como reentrâncias (convexidades voltadas para o pós-país) nos traços horizontais das falhas. Ao simular o desenvolvimento de um sistema de falhas de empurrão que representam um leque imbricado articulado a descolamento basal curvo, em calha sinformal, verificou-se que (i) a curvatura dos traços das falhas mais novas é mais acentuada que a curvatura das mais velhas, (ii) há uma convergência lateral dos traços das falhas, associada a um espaçamento maior dos mesmos na porção central do modelo, onde se verificam as maiores profundidades do descolamento. Os resultados foram comparados às falhas de empurrão do sinclinal de Dom Bosco, porção sul do Quadrilátero Ferrífero, exemplo de um sistema articulado a descolamento basal curvo e com resultados de experimentos físicos, permitindo concluir que, sem exceção, todos os detalhes geométricos das falhas de empurrão geradas encontram equivalentes na natureza e nos modelos analógicos.

Palavras-chave: geologia estrutural, Quadrilátero Ferrífero, modelagem computacional, dobras relacionadas a empurrões

INTRODUÇÃO A geometria, cinemática e dinâmica de falhas de empurrão e dobras a elas geneticamente relacionadas têm sido alvo de grande interesse científico nos últimos anos. Por longo tempo, as falhas de empurrão foram estudadas por meio da sua expressão em seções verticais. Em função do enorme incremento na qualidade do dado sísmico e da disponibilidade cada vez maior de mapas estruturais de elevada precisão, tanto as falhas de empurrão, quanto as demais categorias de falhas, passaram a ser examinadas em três dimensões. Paralelamente, muito ficou conhecido acerca do processo de falhamento.

A mecânica do falhamento prevê que, em meios homogêneos, falhas devem corresponder a superfícies planas ou, no máximo, a associações de segmentos planos. Contudo, isto não ocorre na natureza. Em falhas de empurrão, um dos aspectos geométricos mais característicos, quer de indivíduos isolados, quer de seus sistemas, são os traços curvos pelos quais, geralmente, estão re- 

simulação computacional

presentadas em mapa. Em falhas não planas, as curvas dos traços de falhas de empurrão foram estudadas por vários autores (e.g., Carey 1955, Laubscher 1972, Thomas 1977, Eldredge et al. 1985, Huiqi et al. 1992, Marshak et al. 1992, Marshak \& Wilkerson 1992, Macedo 1997, Macedo \& Marshak 1999, Ribeiro 2001) que, após descrevê-las, lançaram hipóteses para explicar como se desenvolvem e quais os fatores que as controlam. Macedo (1997) e Macedo \& Marshak (1999) sintetizam o conhecimento até então disponível e mostram que cinturões de dobras e cavalgamentos e falhas componentes desenvolvem curvas para satisfazer a diferentes controles tectônicos, que são: (i) variações de espessura ao longo da direção do pacote deformado; (ii) ação de protuberância rígida no pós-país do sistema (indentação) ; (iii) irregularidades das margens continentais em interação; (iv) variações laterais no coeficiente de fricção do descolamento basal do sistema; $(v)$ interação com outras estruturas e conseqüente deformação.

O presente trabalho descreve os resultados de estudo experimental acerca do controle da morfologia do descolamento basal sobre a geometria das falhas de empurrão a ele articuladas. Por meio de simulações geométricas implementadas em programa computacional, o estudo contempla uma abordagem distinta e até então não adotada no entendimento da geometria das falhas de empurrão. Pretende-se demonstrar que, na ausência de indentações e de deformações posteriores, os demais fatores de controle da geometria das falhas de empurrão são, na realidade, reflexos da forma e das propriedades da superfície de descolamento basal.

FALHAS DE EMPURRÃO ESEUS SISTEMAS Juntamente com as dobras, as falhas de empurrão são as estruturas dominantes da arquitetura dos sistemas tectônicos convergentes, ou seja, os orógenos e os prismas acrescionários, onde constituem cinturões de cavalgamento e dobramento. Também ocorrem subodrinados em zonas transcorrentes e nos sistemas continentais invertidos.

Em uma falha de empurrão ideal, distinguem-se dois segmentos (Fig. 1): o patamar ou piso e a rampa, a qual pode ser subdividida em rampa frontal, oblíqua e lateral, em função de sua disposição em relação ao movimento geral do bloco de capa.

Os sistemas de falhas de empurrão (cinturões de dobramento e cavalgamento) exibem a forma geral de uma cunha de seção triangular alongada, no interior da qual os componentes se arranjam, em geral, em leques imbricados vergentes para o antepaís (Oldham 1921, Elliot 1976, Chapple 1978, Boyer \& Elliot 1982, Davis et al. 1983) (Fig. 2). Tais leques podem exibir maior ou menor complexidade geométrica, mas um traço característico é a sua articulação a uma falha basal de baixo ângulo que funciona como piso comum de todos os componentes: o descolamento basal (Fig. 2).

\section{BASESPARA ASIMULAÇÃOCOMPUTACIONAL:OMODE- LOGEOMÉTRICO-CINEMÁTICODA EVOLUÇÃODEUMA DOBRA DE PROPAGAÇÃODE FALHA EM 2D As descrições} dos sistemas naturais e os resultados de experimentos físicos e matemáticos permitem concluir que, durante a nucleação e desenvolvimento, falhas de empurrão e dobras são indissociáveis. Por esta razão, os modelos que descrevem a geração e o desenvolvimento de falhas de empurrão sempre contemplam ambas as formas de acomodação do encurtamento dos pacotes de rochas sob regime compressional. Os modelos existentes e de grande uso têm as seguintes características gerais:

- são bidimensionais;

- são geométrico-cinemáticos, ou seja, prevêem a geometria e

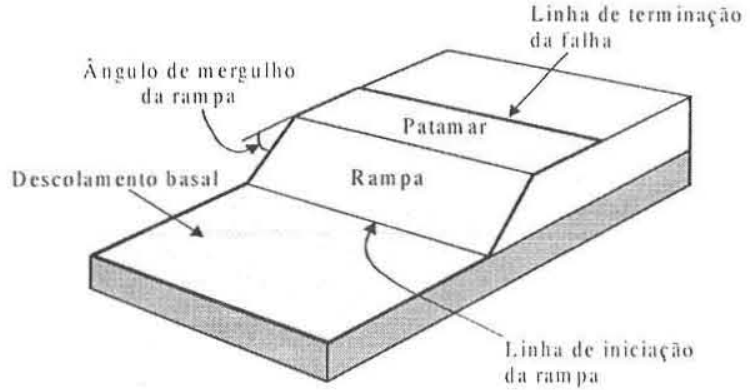

Figura 1-Seção que ilustra os segmentos de una falha de empurrão: patamar inferior, rampa e patamar superior:

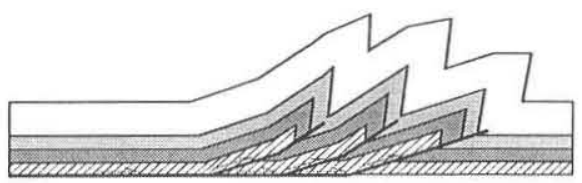

Figura 2-Leque imbricado vergente para o ante-país formado por conjunto de falhas de empurrão articuladas a um descolamento basal.

os movimentos de matéria envolvidos no processo em função de encurtamentos e não das forças envolvidas;

- não consideram propriedades reológicas dos materiais envolvidos;

- partem, em geral, do princípio da conservação da área da seção enfocada.

Como base para as simulações realizadas escolheu-se, dentre os modelos disponíveis na literatura, o conhecido como dobra de propagação de falha. Concebido originalmente por Suppe \& Medwedeff (1990), este modelo descreve, em 2D, o desenvolvimento progressivo de uma falha de empurrão constituída por um patamar (descolamento basal) e uma rampa, em conjunção com o dobramento do bloco de capa (Fig. 3).

Como a maioria dos modelos existentes, o da dobra de propagação de falha está fundamentado no cálculo da migração de kink bands. Como se deduz da figura 3 , a dobra que se desenvolve no bloco de capa da falha é formada por uma associação de kink bands, as quais migram e variam em tamanho com o aumento progressivo do encurtamento transmitido à seção. Concomitantemente, crescem o rejeito da falha de empurrão e o comprimento do segmento de rampa. As camadas situadas além do ponto de terminação superior da falha são contínuas, descrevendo assim uma dobra de cobertura. Já as camadas abaixo deste ponto são truncadas pela rampa.

Este modelo assume ainda que os mergulhos das camadas no interior das várias kinks permaneçam constantes no curso do processo, como o faz o mergulho da rampa da falha (Fig. 3). Outras assunções do modelo são a deformação homogênea, a constância na espessura das camadas e a conservação de área em seções paralelas à direção de encurtamento.

Para o tratamento matemático de uma dobra por propagação de falha é necessário determinar a posição e os ângulos de inclinação de cada uma das kinks bands no curso de todo o desenvolvimento. Equações que permitem obter estes ângulos e posições foram deduzidas por Mitra (1990), Suppe \& Medwedeff (1990) e, posteriormente, rearranjadas, de forma mais facilmente aplicável à computação, por Hardy (1997) e Mercier et al. (1997). Usando 
essas equações e conhecendo a espessura de cada camada, podese calcular, por meio de análise geométrica/analítica, a sua posição após o dobramento/falhamento para qualquer quantidade de encurtamento (variável D da Fig. 3).

\section{CONSTRUÇÃODOMODELOGEOMÉTRICO-CINEMÁTICO DE DOBRAS POR PROPAGAÇÃO DE FALHAS EM 3D Vi-} sando simular, em 3D, a nucleação e evolução de uma falha de empurrão associada a uma dobra de cobertura para o posterior estudo da influência da morfologia do descolamento basal, desenvolveu-se um programa computacional para gerar, a partir de modelos bidimensionais, um modelo tridimensional. A configuração 3D é obtida pela integração de grande número de modelos bidimensionais de dobras de propagação de falha justapostos, separados por distâncias tão pequenas quanto se queira. A junção de pontos entre as seções origina o desenho tridimensional, contendo as camadas, a superfície de descolamento e a rampa da falha, como mostra a figura 4.

O programa para implementar este modelo matemático permite que cada seção do modelo 3D seja criada independente das demais, isto é, para cada seção podem ser definidos, independentemente, os seguintes parâmetros: número de camadas, espessura de cada camada, profundidade do descolamento, local de início da rampa da falha, ângulo de inclinação da rampa da falha e quantidade de encurtamento (Fig. 5). Modificando estes parâmetros é possível criar inúmeras situações geológicas distintas. O programa permite, ainda, obter seções horizontais (mapas) posicionadas em qualquer nível da altura do modelo (Fig. 6).

\section{INFLUÊNCIA DA MORFOLOGIA DA SUPERFÍCIE DE DESCOLAMENTO NA GEOMETRIA DASFALHAS DE EM- PURRÃO E DOBRAS ASSOCIADAS De posse do programa} de simulação, passou-se a executar uma bateria de experimentos nos quais introduziram-se variadas formas de superfície de descolamento e diferentes configurações de camadas na pilha sedimentar a deformar. A figura 7 mostra várias destas configurações, iniciando com uma situação simples, que é a de um conjunto de camadas planas e horizontais assentadas sobre superfície também plana e horizontal, na qual se alojará o descolamento basal.

A todos estes blocos foi aplicado encurtamento total de $20 \%$, o qual foi acomodado no par falha-dobra de cobertura, como previsto no modelo de dobra por propagação de falha. Em todas as simulações utilizou-se o mesmo mergulho para a falha $\left(20^{\circ}\right)$ e o mesmo ponto de iniciação de rampa. Os mapas geológicos resultantes destas simulações são mostrados na figura 8 , com a sua localização no respectivo modelo.
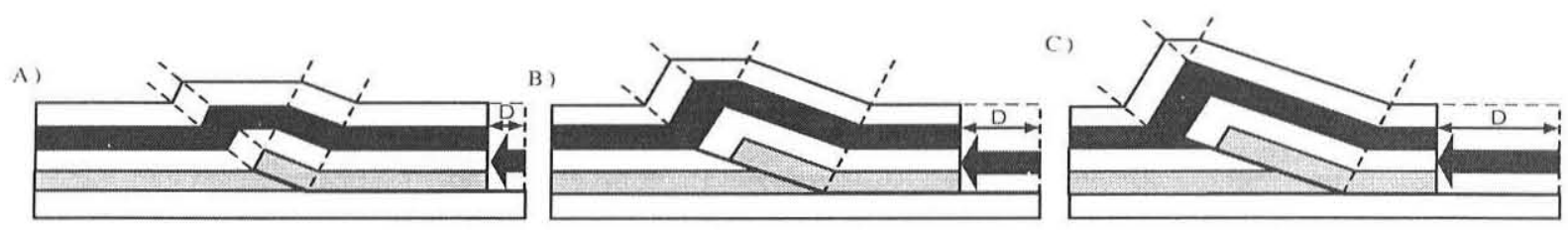

Figura 3 - Desenvolvimento de uma dobra por propagação de falha (modelo de espessura constante das camadas). Modificado de Mosar \& Suppe (1992).

A)

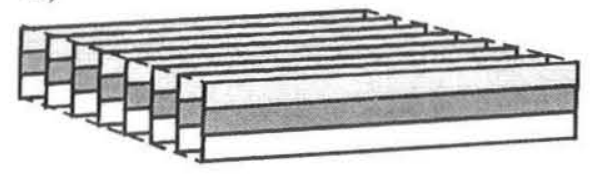

B)

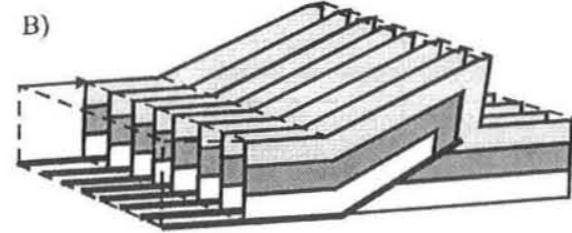

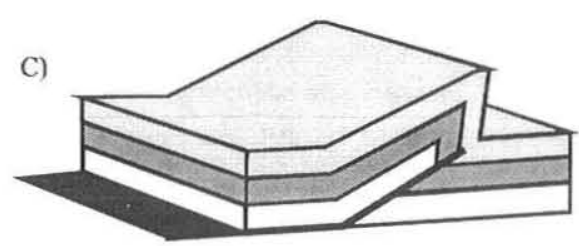

Figura 4 - Geração de modelos 3D a partir da integração de seções verticais longitudinais. O bloco diagrama representa um modelo geológico contendo três camadas de espessura uniforme. (A) Seções verticais longitudinais no estágio não deformado; (B) As mesmas seções após o desenvolvimento de uma dobra por propagação de falha; (C) Modelo final obtido pela integração das seções verticais.

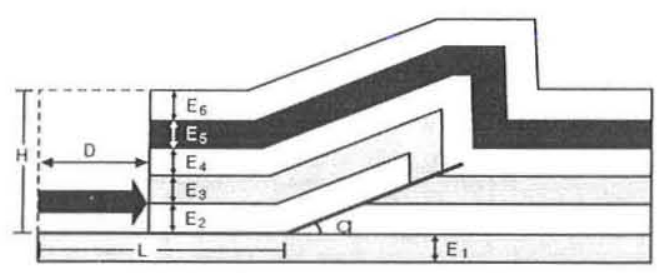

Figura 5 - Seção bidimensional ilustrando os parâmetros que podem ser modificados durante uma simulação computacional de dobra por propagação de falha em modelo com seis camadas. $E_{n}=$ Espessura de cada camada. $D=$ Quantidade de encurtamento. $H=$ Profundidade do descolamento. $L=$ Ponto de iniciação da rampa da falha. $q=$ Ângulo de inclinação da rampa da falha.
Do exame dos mapas da figura 8, emergem diversas conclusões. Primeiro, é notável como seções verticais isoladas pouco refletem a geometria geral dos sistemas de falhas. Segundo, também é notável como, nestas condições, o traço da rampa de falha em mapa é fiel espelho da topografia da superfície de descolamento. $\mathrm{O}$ traço da falha é retilíneo, quando a superfície de descolamento é plana; é curvo, quando a superfície é curva; e:

- convexidades da superfície de descolamento (altos) se expressam como saliências (convexidades voltadas para o antepaís) nos traços horizontais das falhas;

- concavidades da superfície de descolamento (baixos) se expressam como reentrâncias (convexidades voltadas para o póspaís) nos traços horizontais das falhas;

- os pontos de culminância das saliências e reentrâncias dos traços horizontais das falhas correspondem a pontos de 


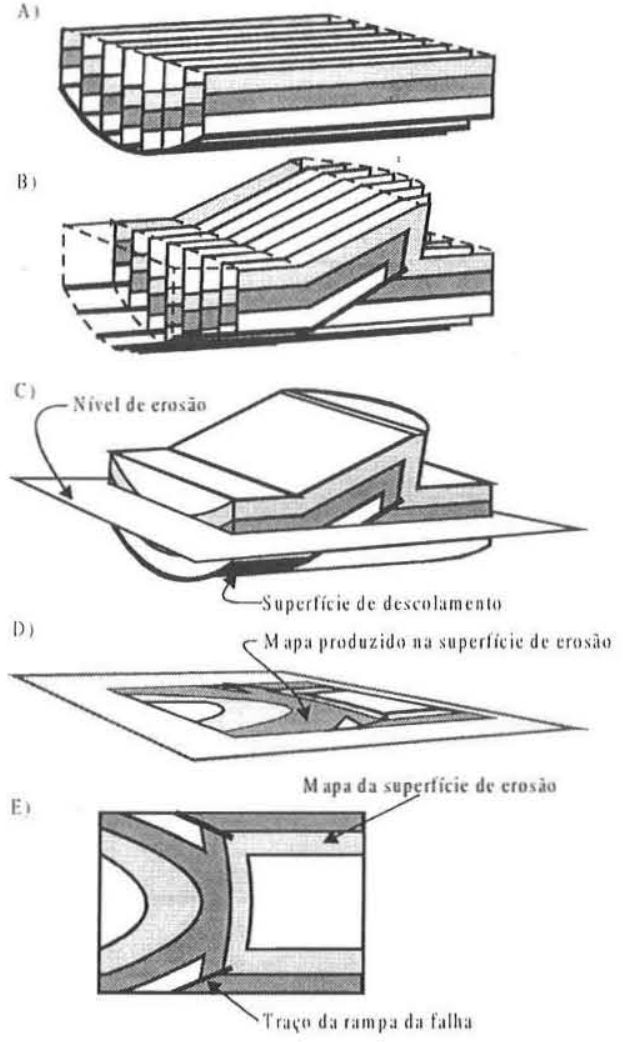

Figura 6 - Ilustração do processo e dos resultados da simulação computacional de dobra associada a falha. (A) Série de seções longitudinais de uma bacia em calha sinformal. (B) A dobra por propagação de falha se desenvolve em cada seção após um estágio de compressão. (C) Modelo tridimensional obtido pela integração das seções do estágio anterior: (D) Visão em perspectiva de mapa geológico gerado no nível de erosão assinalado em C. (E) Mapa geológico da seção horizontal do modelo tridimensional.

culminação, respectivamente, dos baixos e altos da superfície de descolamento.

Dois fatos concorrem para esta correspondência entre morfologia do descolamento basal e traço horizontal das falhas de empurrão. Primeiro, se uma rampa de falha de mergulho constante se inicia sobre superfície irregular, sua linha de iniciação não será reta. Não sendo a linha de iniciação da rampa reta, a superfície da falha não será plana, mas sim uma superfície qualquer, tal como mostra a figura 9. Assim, se a linha de iniciação da rampa descreve um arco voltado para baixo (o que corresponderia a um baixo na superfície de descolamento), a rampa adquire convexidade voltada para o antepaís (Fig. 9). Se, ao contrário, a linha de iniciação da rampa descrever arco voltado para cima (o que corresponderia a um alto na superfície de descolamento), a rampa da falha de empurrão descreverá convexidade voltada para o pós-país.

Segundo, há uma relação entre a profundidade da superfície de descolamento e o ponto de emersão da rampa de falha em uma dada seção horizontal (Marshak \& Wilkerson 1992), isto é, existe uma relação entre a espessura do pacote de rocha envolvido na deformação e o ponto de afloramento da rampa de falha em qualquer nível de erosão considerado. Esta relação está mostrada na

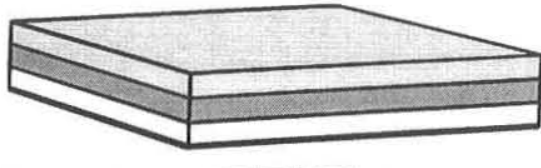

B)

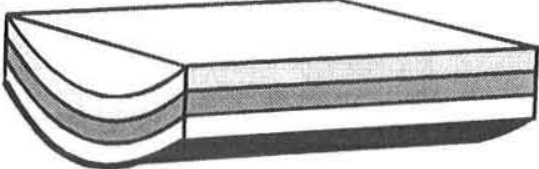

C)

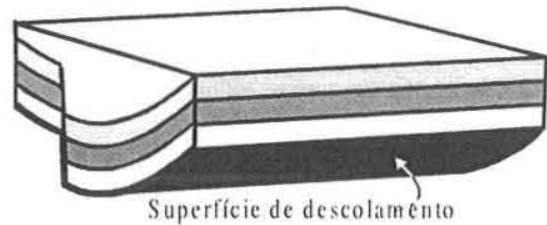

D)

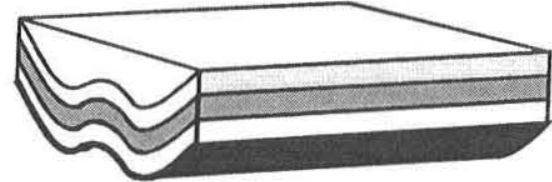

E)

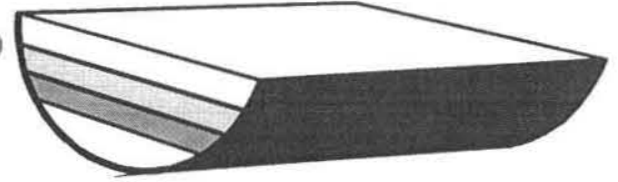

Figura 7-Blocos-diagrama mostrando diferentes configurações de pilhas sedimentares a serem submetidas ao falhamento. Observar as diferentes configurações das superfícies de descolamento e das camadas. (A) Camadas e plano de descolamento planos. (B) Sinclinal com plano de descolamento acompanhando a base da camada mais profunda. (C) Falha normal atingindo as camadas da base de um sinclinal. (D) Sinclinal com um anticlinal no seu centro. O plano de descolamento acompanha a forma das camadas. (E) Bacia sedimentar progradante. O plano de descolamento acompanha o contato dos sedimentos com o embasamento da bacia.

figura 10. Profundidades $(\mathrm{H})$ maiores do descolamento, que automaticamente implicam espessuras maiores do pacote de rochas, resultam em distância horizontal (d) maior entre o ponto de início da rampa e o seu ponto de emersão sobre o plano horizontal considerado (Fig. 10). Na figura 10, qualquer variação em $\mathrm{H}$ se reflete em d, segundo a equação (1):

$$
\mathrm{d}=\mathrm{H} / \operatorname{tgq}
$$

onde q é o mergulho da rampa.

Este efeito da variação de espessura se sobrepõe ao da sinuosidade da linha de iniciação da rampa e termina por acentuar as saliências e reentrâncias dos traços horizontais das rampas das falhas de empurrão. Pequenas variações em $\mathrm{H}$ são ampliadas como variações maiores em d para ângulos de rampa (q) menores que $45^{\circ}$, já que as tangentes desses ângulos são menores que 1. Devido a esse efeito de ampliação, a curvatura dos traços das falhas em mapa é, em geral, maior que a curvatura da superfície de descolamento. Nos modelos das figuras $8 \mathrm{~B}$ a $8 \mathrm{E}$, por exemplo, como a calha preenchida tem o topo plano, os pontos de máxima profundidade correspondem às maiores espessuras; assim, segmentos de rampa que neles se iniciam serão projetados, em plano horizontal qualquer, mais à frente do que seus vizinhos situados a 
profundidades menores, uma vez que o ângulo de mergulho da rampa é constante.

Feições interessantes podem também ser observadas nos traços horizontais das diversas camadas dos blocos de capa da faIhas dos modelos reproduzidos na figura 8. Exceto no modelo 8A, os contatos entre camadas desenham padrões relativamente complexos nos mapas, sendo alguns deles típicos de interferência de

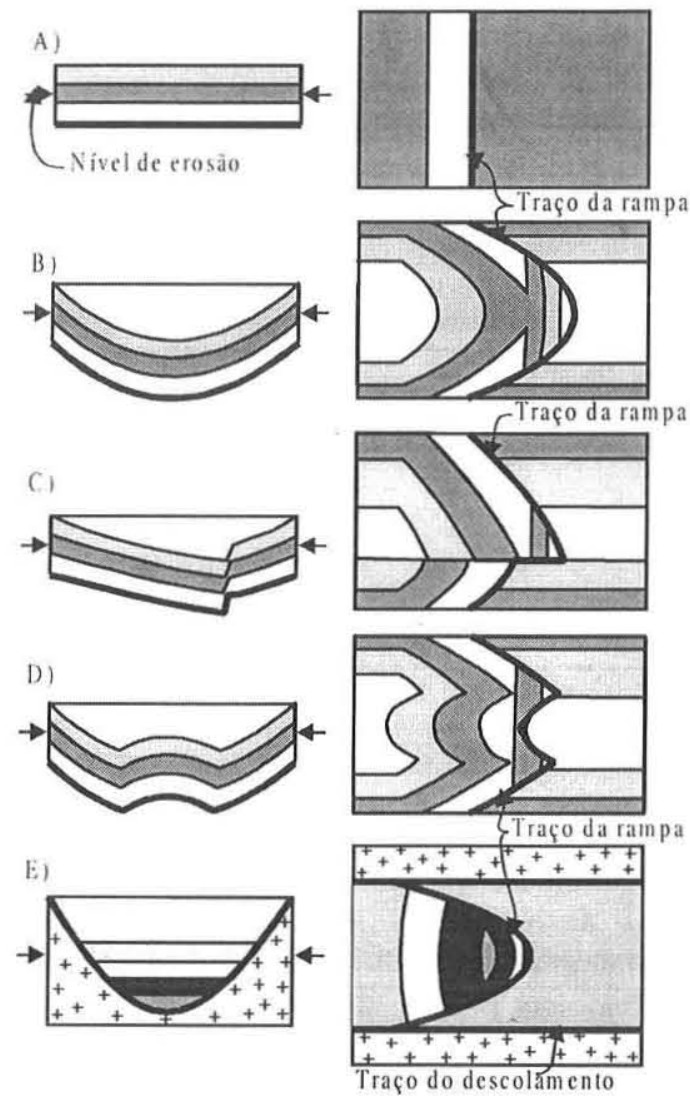

Figura 8 - Diferentes morfologias da superfície de descolamento e sua expressão nos traços em mapa das falhas associadas. As ilustrações da esquerda mostram seções transversais dos modelos antes da deformação. As ilustrações da direita são as respectivas seções horizontais dos modelos após o desenvolvimento da dobra por propagação de falha, em resposta à compressão com encurtamento de $20 \%$. As rampas de falhas mergulham $20^{\circ}$. As setas nas seções transversais indicam o nivel de erosão onde foram produzidas as seções horizontais.

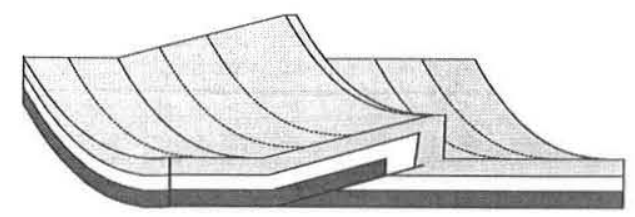

Figura 9 - Bloco diagrama mostrando uma dobra por propagação de falha que afeta camadas anteriormente dobradas. $O$ descolamento basal é paralelo as camadas e é superfície curva. Nesse caso a dobra relacionada à falha tem charneira curva (depressão antiformal) que segue a curvatura do descolamento.

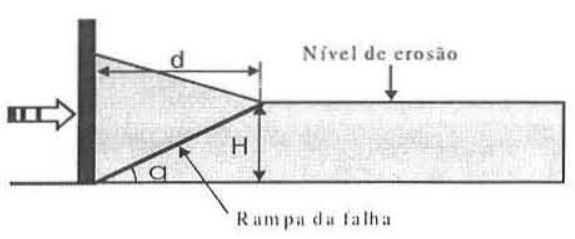

Figura 10 - Relação entre as variáveis d (distância horizontal entre o ponto de início da rampa e o seu ponto de surgimento no nível de erosão), $p$ (profundidade do descolamento) e $q$ (ângulo de inclinação da rampa).

dobras. De fato, no caso dos modelos $8 \mathrm{~B}, 8 \mathrm{C}$ e $8 \mathrm{D}$, as camadas já se encontravam deformadas antes do falhamento. Como no bloco de capa sempre se desenvolve anticlinal, surgirão ali padrões de interferência e, conseqüentemente, complexos desenhos de traços horizontais.

Observa-se, entretanto, uma complexidade relativamente menor nos traços das camadas no modelo $8 \mathrm{E}$. Isto se deve a que, neste caso, as camadas não terem sido previamente deformadas. É importante notar, porém, que sendo o descolamento curvo, a rampa será curva, o que fará com que o anticlinal desenvolvido na capa não tenha a charneira retilínea, mas também curva, acompanhando a linha de iniciação da rampa, tal como é mostrado na figura 9. Por isto, os traços horizontais das camadas no modelo da figura $8 \mathrm{E}$ são também curvos.

As simulações mostram que a maior ou menor complexidade dos traços das falhas e dobras associadas, em planta, são função também dos valores de encurtamento. Isto pode ser deduzido do exame da figura 11, a qual mostra vários estágios da evolução, em mapa, de uma dobra de propagação de falha, desenvolvida sobre descolamento curvo, em forma de calha sinformal cilíndrica, como a da figura 8B. O nível de corte das seções horizontais está também assinalado na figura $8 \mathrm{~B}$. Na figura $11 \mathrm{~A}$ vê-se o estado inicial não deformado. Os mapas seguintes (Figs. $11 \mathrm{~B}$ a $11 \mathrm{G}$ ) foram produzidos a incrementos de encurtamento de $5 \%$.

Algumas feições interessantes podem ser observados na figura 11 . O traço da rampa da falha aparece aos poucos, das laterais para o centro, até assumir sua forma curva final (Fig. 11E). O traço emerge primeiro nos domínios de menores espessuras, avançando progressivamente para os relativamente mais espessos. Por outro lado, as camadas mais velhas começam a se manifestar, em mapa, como cunhas laterais (Figs. 11B, 11C, 11D e 11E) que se inserem cada vez mais, até formar uma curva contínua (Fig. 11F), acompanhando a forma do traço da rampa da falha.

A diferença de curvatura dos contatos entre as camadas mais próximas e as mais afastadas do traço da falha (Figs. 11D, 11E e $11 \mathrm{~F})$, resulta das diferenças entre os ângulos e os sentidos de mergulho das mesmas. As camadas próximas à falha têm mergulho alto e voltado para o antepaís, por participarem do flanco curto, frontal, da dobra por propagação de falha. As demais mergulham para o pós-país, com ângulos menores. A figura $11 \mathrm{G}$ representa estágio evolutivo para o qual o encurtamento foi suficiente grande para não aparecer mais, neste nível erosional, o flanco frontal da dobra. Os contatos são, então, curvos e paralelos à falha.

SIMULAÇÃODA FORMAÇÃODESISTEMA DEFALHASDE EMPURRÃOASSOCIADOA DESCOLAMENTOBASALNÃO PLANO Os sistemas naturais de falhas de empurrão e os produ- 

simulação computacional

zidos em experimentos físicos tendem a ter encurtamentos acomodados em várias falhas e respectivas dobras e também a que estas falhas se desenvolvam pelo colapso da lapa. Ou seja, as falhas se formam segundo uma seqüência tal que o movimento cessa em uma dada falha, iniciando-se logo a seguir em nova, nucleada na sua lapa, e assim por diante. O resultado final é, em geral, um leque imbricado de falhas de empurrão, todas articuladas a um descolamento basal, como mostrado na figura 2 .

O programa computacional escrito para este estudo permite que se simule o desenvolvimento de um conjunto de falhas como mostra a figura 12. Aqui também, para se ter uma base de comparação, utilizou-se uma pilha de camadas pré-deformadas em sinforme. O descolamento basal foi alojado na base do pacote e sua forma foi de calha cilíndrica. O mapa e a seção longitudinal, para $50 \%$ de encurtamento, estão mostrados nas figuras $12 \mathrm{~B}$ e $12 \mathrm{C}$, respectivamente.

Examinando a seção horizontal da figura 12B, observa-se, além das feições descritas, que:

- a curvatura dos traços das falhas mais novas é mais acentuada que a curvatura das falhas mais velhas;

- há uma convergência lateral dos traços das falhas, associada a espaçamento maior dos mesmos na porção central do modelo, onde ocorrem as maiores espessuras.

Comparando, na figura 12, o mapa com a seção longitudinal, conclui-se que a diminuição da curvatura dos traços em direção ao pós-país resulta do aumento progressivo do mergulho das falhas mais velhas. Isto ocorre devido a estas serem inativas e pertencentes ao bloco de capa da falha mais nova, experimentando, nessa condição, rotação progressiva em direção ao pós-país.

\section{FALHASDEEMPURRÃODOSINCLINAL DEDOM BOSCO, PORÇÃOSULDOQUADRILÁTEROFERRÍFERO:EXEMPLO DESISTEMA ARTICULADO A DESCOLAMENTO BASAL}

CURVO A porção sul do Quadrilátero Ferrífero, região central de Minas Gerais, é dominada pelo Sinclinal de Dom Bosco (Johnson 1962, Dorr 1969, Barbosa 1969) (Fig. 13). Trata-se de complexo sinclinal de traço axial aproximadamente E-W no interior do qual ocorre um sistema de falhas de traço curvo, com saliências voltadas para oeste (Fig. 13). Estas falhas se articulam, a sul, à Falha do Engenho (Guild 1957), que ocorre em todo o flanco sul do sinclinal. A norte, as falhas internas conectam-se a uma zona de cisalhamento dúctil instalada na aba norte do sinclinal e que envolve, na Serra de Ouro Preto, as rochas das Formações Moeda, Batatal e a porção basal da Formação Cauê do Supergrupo Minas
(Fig. 13). Cartografadas por Johnson (1962) e Barbosa (1969), estas falhas foram descritas pelo primeiro autor como "falhas em forma de canoa".

Chemale Jr. et al. (1991), fundamentados na análise cinemática, demonstram que o Sinclinal de Dom Bosco foi gerado em uma primeira fase de deformação, à qual sobreveio a nucleação da FaIha do Engenho e falhas curvas associadas. Ter-se-ia, então, o sinclinal preexistente, no interior do qual se desenvolveu o sistema de falhas de empurrão. Segundo estes autores, o sistema de falhas teria se originado em resposta a campo compressional E-W, durante o Brasiliano. Assim, a estrutura é excelente exemplo de sistema de falhas de empurrão gerado pelo fluxo de material no interior de calha sinformal preexistente, tal como simulado e mostrado na figura 12 .

As falhas desenvolvidas no interior do Sinclinal de Dom Bosco (Fig. 13) possuem traços curvilíneos com extensas rampas laterais. Ademais, são assimétricas e com as rampas do sul mais desenvolvidas do que as do norte. O acervo de indicadores cinemáticos atesta transporte de ESE para WNW, com a lineação de estiramento posicionada, preferencialmente, em S80E $30^{\circ}$, ligeiramente oblíqua à calha do sinclinal. A falha envoltória do Engenho tem mergulhos variáveis para norte e os indicadores cinemáticos associados atestam movimentos sinistrais a reversos sinistrais. A zona de cisalhamento envoltória da Serra do Ouro Preto, ao contrário, exibe indicadores de movimentos destrais a reversos destrais. (Chemale Jr et al. 1991, Ribeiro \& Alkmim 1997).

Nos modelos computacionais de calha sinformal preexistente submetida a encurtamento axial, se formou um sistema de falhas curvas associadas a dobras (Fig. 12). As falhas geradas são curvas e os seus traços em planta convergem lateralmente, mostrando grande saliência voltada para o antepaís, cuja culminação coincide com o traço axial da dobra preexistente. Os contatos entre as diversas unidades envolvidas desenham padrões complexos nos mapas, marcados pela presença de cunhas laterais das camadas inferiores. Nestas simulações, os modelos são lateralmente limitados, como se as rampas laterais das falhas de empurrão fossem superfícies verticais e planas. Ao longo destas ocorrem movimentos direcionais a oblíquos, destrais em uma e sinistrais em outra. Estas características ocorrem no sistema de falhas do Sinclinal de Dom Bosco, como se deduz comparando as figuras 12 e 13.

Duas feições peculiares do Sinclinal de Dom Bosco não se reproduziram nos modelos. Uma é a deriva sistemática para norte (sinistral) da zona de charneira do sinclinal ao longo das falhas de empurrão, como mostra a figura 13, pelo deslocamento sistemáti-
A)

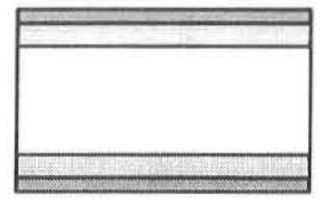

E)

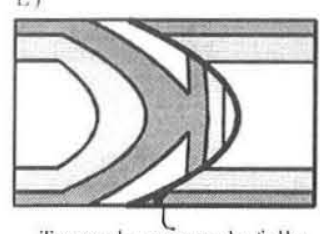

Traço da rampa da falha
B)

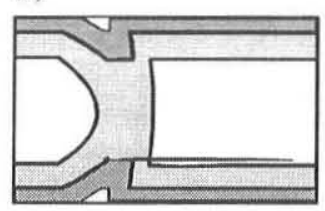

F)

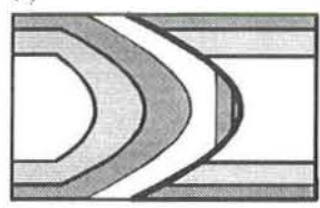

C) Traço da rampa da falha

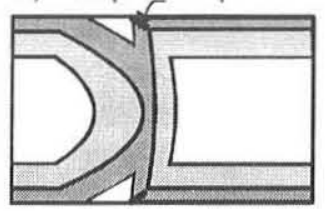

G)

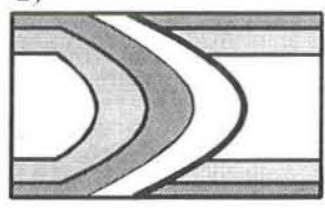

D)

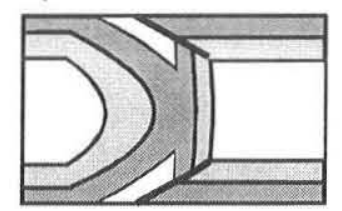

centes de encurtamento. O descolamento tem forma curva elíptica em seção transversal, como mostra o esquema da figura $7 B$ e as camadas seguem sua morfologia. A rampa de falha mergulha $20^{\circ}$. (A) Estágio não deformado. Encurtamento: (B) $5 \%$, (C) $10 \%$, (D) $15 \%$, (E) $20 \%,(F) 25 \%$ e (G) $30 \%$. 
co do traço axial no mesmo sentido. Outra está relacionada à distribuição das unidades estratigráficas. $\mathrm{O}$ mapa da figura 13 , mostra, na porção sul, a unidade mais jovem (Grupo Itacolomi) junto à borda do sistema de falhas. No modelo, à medida que se desloca das bordas para o centro da calha sinformal, passa-se, ao contrário do observado, a camadas cada vez mais novas (Fig. 12).

A primeira discrepância é o resultado do movimento oblíquo das escamas de empurrão no interior do Sinclinal de Dom Bosco,

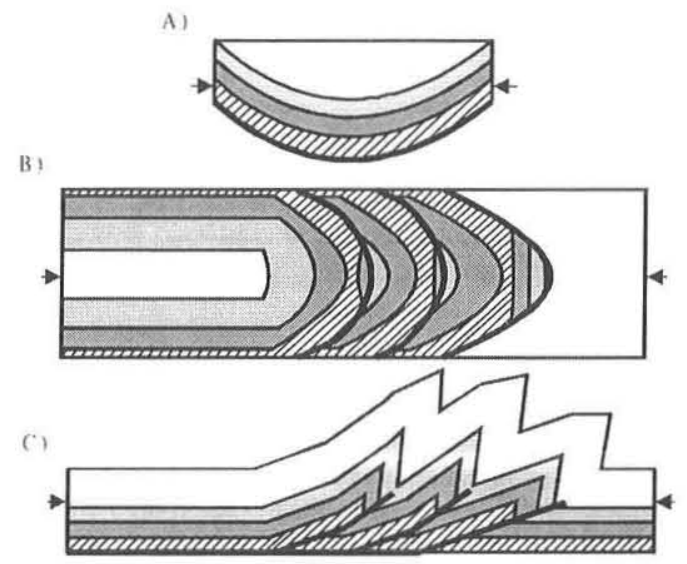

Figura 12 - Seções produzidas em modelo 3D de um leque imbricado contendo três falhas e dobras por propagação de falha correlatas. Todas as rampas de falhas tinham, inicialmente, o mesmo mergulho de $20^{\circ}$. A compressão gerou encurtamento de 50\%. (A) Seção transversal do modelo não deformado, mostrando a configuração de sinclinal com a superfície de descolamento paralelo à camada mais profunda. (B) Mapa geológico. (C) Seção longitudinal sem exagero vertical. As setas no mapa indicam a posição da seção longitudinal e as na seção transversal indicam o nível de produção do mapa geológico. As falhas mais novas são as situadas mais à direita nas ilustrações. que não foi introduzido nos modelos. Neles, o movimento foi estritamente paralelo ao eixo da calha preexistente. A segunda, resulta da posição discordante do Grupo Itacolomi em relação às unidades mais velhas. $\mathrm{O}$ exame da figura 13 mostra que as rochas Itacolomi jazem sobre as mais diversas unidades.

DISCUSSÃO E CONCLUSÕES Os resultados aqui obtidos comparados com os de sistemas naturais de falhas descritos na literatura e com os resultados de experimentos físicos permitem concluir que, sem exceção, todos os detalhes geométricos das falhas de empurrão geradas encontram equivalentes na natureza e nos modelos analógicos. Por exemplo, os resultados obtidos estão de acordo e até complementam os apresentados por Marshak \& Wilkerson (1992), Marshak et al. (1992), Macedo (1997), Macedo \& Marshak (1999) e Ribeiro (2001). As simplificações introduzidas nesta simulação não as invalidam e tiveram como finalidade isolar efeitos e investigar, em primeira aproximação, o impacto da forma do descolamento basal sobre a geometria das falhas de empurrão e dobras associadas.

A complementação dos resultados dos estudos prévios advém do fato de que a causa última da morfologia curva de falhas de empurrão, na ausência de acentuadas heterogeneidades no pacote de rochas, de indentação atuando no pós-país e de deformações posteriores, é a forma da superfície de descolamento, e não propriamente a variação de espessura do pacote de rochas deformado. Em superfície de descolamento basal dotada de irregularidades, a linha de iniciação de rampa não será retilínea e as falhas a ela articuladas não serão planas. As variações de espessura do pacote serão, na realidade, conseqüência destas irregularidades e acentuam a curvatura dos traços em planta. Assim, variações de espessura por si só não são, em geral, capazes de gerar rampas curvas em falhas de empurrão. Para ocasionar variações de espessura ao longo da direção do pacote, com superfície de descolamento plana e horizontal, é necessária a existência de variações topográficas. Neste caso, as falhas serão planas e a curvaturas de seus
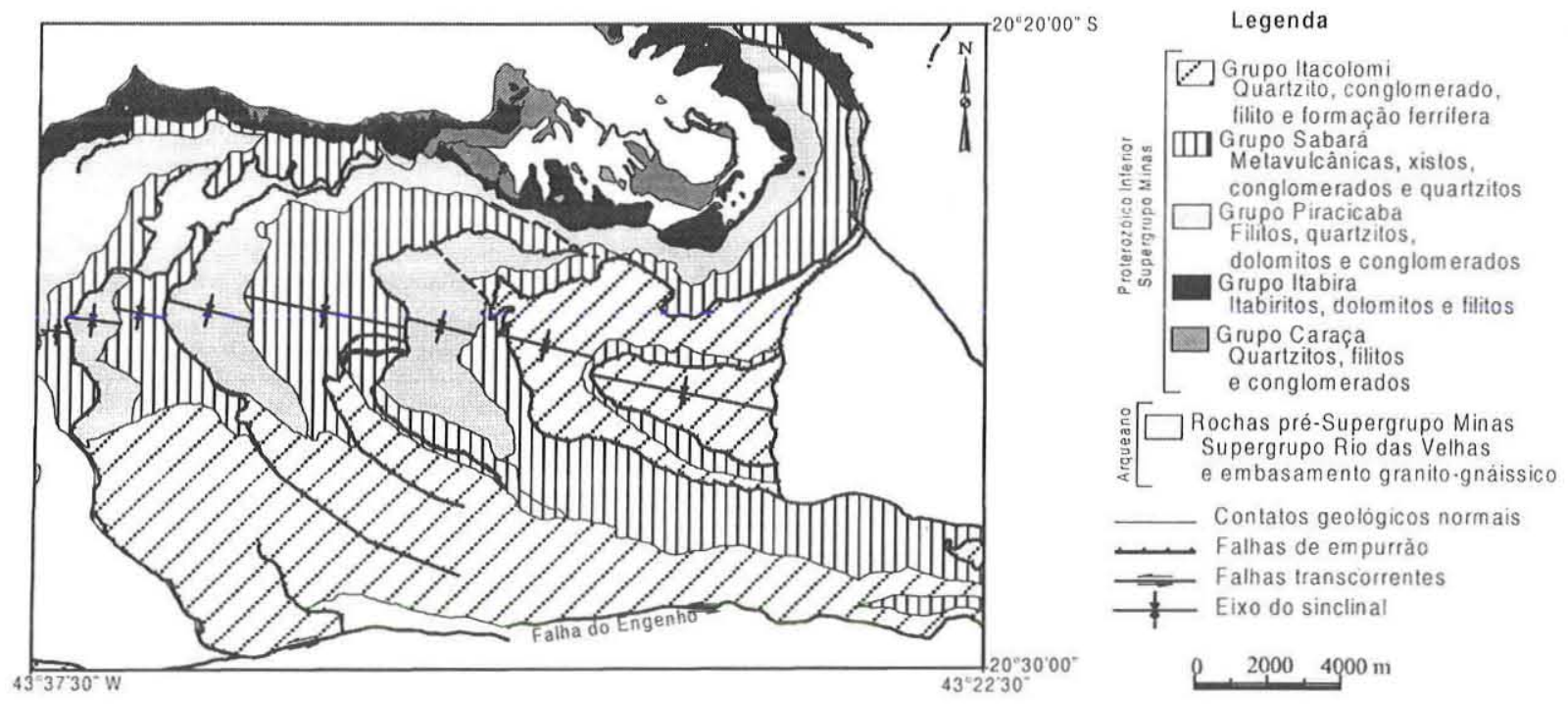

Figura 13 - Mapa geológico do sistema de falhas do Sinclinal de Dom Bosco, na porção sul do Quadrilátero Ferrífero, Minas Gerais. No interior do sinclinal desenvolveu-se um sistema de falhas de traço curvo, com saliências voltadas para oeste. Mapa compilado de Jolunson (1962), Dorr (1969) e Barbosa (1969), com modificações. 
traços refletirão somente variações topográficas.

Menciona-se, ainda, que, mesmo que o descolamento basal seja plano e horizontal e que não haja indentantes e deformações posteriores, as rampas articuladas podem ser curvas, quando uma outra condição é satisfeita.

Como demonstra Ribeiro (2001), em extensão a resultados antes obtidos (Huiqi et al. 1992, Macedo \& Marshak 1999), se há variações laterais significativas do coeficiente de fricção do descolamento basal, a linha de iniciação de rampa, mesmo que contida na superfície plana e horizontal do descolamento, poderá não ser retilínea e, assim, não serão planas as rampas articuladas. Ribeiro (2001) verificou que aumentos laterais no coeficiente de friç̧ão do descolamento basal resultam no recuo da linha de iniciação da rampa em direção ao pós-país. Já diminuições, ao contrário, fazem-na avançar em direção ao antepaís.

Assim, a conclusão alcançada com a simulação geométrico- computacional é a de que, na ausência de indentações no póspaís de deformações posteriores e de acentuadas heterogeneidades na pilha de rochas envolvidas, a geometria 3D de falhas individuais, seus sistemas e dobras associadas dependem da morfologia e variações do coeficiente de fricção da superfície de descolamento à qual se associam. Nestas condições, o traço horizontal das falhas de empurrão e estruturas associadas refletem a morfologia e as propriedades mecânicas do descolamento basal.

Agradecimentos A Frederico M. Ribeiro pelas discussões ao longo do trabalho. A CAPES pela bolsa de estudos para Vassily K. Rolim. A FAPEMIG, pelo apoio (Proj. CEX2024/96) a este estudo. A TEXACO Inc., representada pelo Dr. Stephen C. Hook, do setor de Geologia Estrutural em Houston, pelo apoio financeiro e autorização para a divulgação dos resultados. Aos revisores da RBG pelas sugestões ao manuscrito.

\section{Referências}

Barbosa A.L.M. 1969. Geologic map of Ouro Preto and Santa Rita de Ouro Preto quadrangles, Minas Gerais, Brazil. U.S. Geol. Survey: Prof. Paper, 641-A: plate 9.

Boyer S.E. \& Elliott D. 1982. Thrust systems. American Association of Petroleum Geologists Bulletin. 66: 1 196-1230.

Carey S.W. 1955. The orocline concept in geotectonics. Pap. Proc. R. Soc. Tasmania, 89:255-289.

Chapple W.M. 1978. Mechanics of thin-skinned fold-and-thrust belts. Geol. Soc. Am. Bull., 89:1189-1198.

Chemale Jr. F., Rosière C.A., Endo I. 1991. Evolução tectônica do Quadrilátero Ferrífero, Minas Gerais: um modelo. Pesquisas, 18(2): 104-127.

Davis G.A., Suppe J., Dahlen F.A. 1983. Mechanics of fold and thrust belts and accretionary wedges. J. Geophys. Res, 88:1153-1172.

Dorr J.V.N. 1969. Physiographic, stratigraphic and structural development of the Quadrilátero Ferrífero, Minas Gerais, Brazil. USGS Prof. Paper, 641-A.

Eldredge S.. Bachtadse V.. Van der Voo R. 1985. Paleomagnetism and the orocline hypothesis. Tectonophysics, 119:153-179.

Elliott D. 1976. The motion of thrust sheets. J. Geophys. Res., 81:949963.

Guild P.W. 1957. Geology and mineral resources of the Congonhas district, Minas Gerais, Brazil. USGS Prof. Paper, 290:1-90.

Hardy S. 1997. A velocity description of constant-thickness faultpropagation folding. Journal of Structural Geology, 19:893-896.

Huiqi L., McClay K.R., Powell D. 1992. Physical models of thrust wedges. In: K.R. McClay (ed.) Thrust Tectonics. Chapman \& Hall. London, pp.: 71-82.

Johnson R.F. 1962. Geology and ore deposits of the Cachoeira do Campo, Dom Bosco, and Ouro Branco quadrangles, Minas Gerais, Brazil. USGS Prof. Paper, 341-B.

Laubscher H.P. 1972. Some overall aspects of the Jura dynamics. Amer: Journ. Sci., 272:293-304

Macedo J.M. 1997. Models of continental fold-thrust belt salients. PhD
Thesis, University of Illinois, 295 p.

Macedo J.M. \& Marshak S. 1999. Controls on the geometry of foldthrust belt salients. GSA Bull., 111: 1808-1822.

Marshak S. \& Wilkerson S. 1992. Effects of overburden thickness on thrust belt geometry and development. Tectonics, 11:560-566.

Marshak S., Wilkerson S., Hsui, A. 1992. Generation of curved foldthrust belts: insight from simple physical and analytical models. In: K.R. McClay (ed.) Thrust Tectonics. Chapman \& Hall, London. pp.: 83-92.

Mercier E., Outtani F., Frizon de Lamotte D. 1997. Late-stage evolution of fault-propagation folds: principles and example. J. Structural Geol., 19:185-193.

Mitra S. 1990. Fault-propagation folds: geometry, kinematic evolution ad hydrocarbon traps. ASPG Bull., 74:921-945.

Mosar J. \& Suppe J. 1992. Role of shear in fault-propagation folding. In: K.R. McClay (ed.) Thrust Tectonics. Chapman \& Hall, London, pp.:123-137.

Oldham R.D. 1921. Know your faults. Quart. J. Geol. Soc., 77:xxvii-xcii.

Ribeiro F.M. 2001. A geometria tridimensional de falhas de empurrāo investigada através de modelagem física analógica. Tese de Doutoramento, Escola de Minas, Universidade Federal de Ouro Preto. $311 \mathrm{p}$.

Ribeiro F.M. \& Alkmim F.F. 1997. O sistema de falhas de empurrão do Sinclinal de Dom Bosco, porção sul do Quadrilátero Ferrífero (MG), em modelagens físicas 3D. In: SBG, Simp. Geol. Minas Gerais, 9. Anais, 14:74-76.

Suppe J. \& Medwedeff D.A. 1990. Geometry and kinematics of faultpropagation folding. Eclogae Geologicae Helvetiae, 83:409-454.

Thomas W.A. 1977. Evolution of Appalachian-Ouachita salients and recesses from reentrants and promontories in the continental margin. Amer. Journ. Sci., 277: 1233-1278.

Manuscrito A-1318

Recebido em 15 de janeiro de 2002

Revisão dos autores em 10 de abril de 2004

Revisão aceita em 10 de maio de 2004 